\title{
INICIATIVAS PARA PROMOÇÃO DO ACESSO À JUSTIÇA \\ E SUA APLICAÇÃO NO ESTADO DE SANTA CATARINA
}

\author{
Jessé Alberto Schweitzer ${ }^{1}$ \\ Resumo: Frente à reconhecida lentidão do Poder \\ Judiciário e à crescente demanda no ajuizamento \\ de ações, que causa imenso descrédito da popu- \\ lação naquele órgão, a identificação de obstá- \\ culos e o desenvolvimento de meios capazes de \\ promover e ampliar o acesso à justiça é tema de \\ fundamental importância quando se busca dar \\ efetividade aos ditames constitucionais. Especi- \\ ficamente no Estado de Santa Catarina, pode-se \\ observar que as barreiras existentes possuem \\ contorno mais brando, e as iniciativas de desen- \\ volvimento do acesso à justiça encontram força e \\ efetividade. O ponto negativo fica registrado pela \\ ausência de Defensoria Pública neste ente federa- \\ tivo.
}

Palavras-chave: Acesso à justiça. Assistência jurídica. Juizados especiais. Defensoria pública. Estado de Santa Catarina.

\section{INTRODUÇÃO}

O principal meio de resolução de conflitos existente no mundo e, principalmente no Brasil, é o processo judicial.

1 Bacharel em Direito pelo Complexo de Ensino Superior de Santa Catarina - CESUSC. Assessor de Gabinete no Tribunal de Justiça de Santa Catarina. E-mail: jessealberto@gmail.com 
Através de um Poder delegado pelo povo ao Judiciário, este faz às vezes de um terceiro imparcial, dotado do poder de coerção, capaz de por fim aos litígios levados a ele.

No entanto, o Poder Judiciário Brasileiro é reconhecidamente lento e burocrático. As inúmeras possibilidades de recursos, assim como a falta de medidas efetivas que garantam os direitos da população, geram um imenso descrédito da sociedade em relação a essa atividade exercida pelo Estado. Isso, sem contar a falta de funcionários, as custas judiciais e honorários de advogados, assim como os meios arcaicos de produção de atos e demais entraves que retardam a tutela jurisdicional e afastam os cidadãos dos seus direitos.

Em um mundo em constante mutação, onde a tecnologia é responsável por mudar hábitos sociais e promover avanços, não há mais espaço para conservadorismos exacerbados e burocracia demasiada. Por isso, o meio jurídico também precisa estar atento a essa nova ordem mundial e se determinar a desenvolver novos métodos e tecnologias que promovam o acesso à justiça e minimizem esses entraves que impedem a população de ver seus direitos efetivados.

Cabe ressaltar que, qualquer abordagem sobre o assunto deve estar em consonância com o que preceitua a Constituição da República Federativa do Brasil e os códigos processuais, aliadas às condições financeiras do Estado em disponibilizar esses novos instrumentos.

Por isso, o foco deste trabalho se dirige ao estudo de métodos e ideias para a promoção do acesso à justiça, baseado no que preceitua a Constituição e a legislação sobre o assunto, para ao final analisar como está a situação no Estado de Santa Catarina. Para tanto, deve-se estabelecer conceitos, identificar obstáculos e apresentar os meios já existentes de promoção e incentivo a esse instituto. 


\section{CONCEITOS DE ACESSO À JUSTIÇA}

Em linhas gerais, a forma como a população entra em contato com o serviço jurisdicional ofertado pelo Estado é chamada de acesso à justiça. No entanto, o conceito de acesso à justiça não está resumido a esse simples contato.

Para Maria Aparecida Lucca Caovilla (2003, p. 35) a expressão "acesso à justiça" não se resume apenas no acesso ao Poder Judiciário, mas sim em conscientizar a população de que o seu real significado consiste em obter a justiça social.

Mauro Cappelletti e Bryant Garth (1988, p. 12) trazem em seu livro, Acesso à Justiça, a seguinte definição: "O acesso à justiça pode, portanto, ser encarado como o requisito fundamental - o mais básico dos direitos humanos - de um sistema jurídico moderno e igualitário que pretenda garantir, e não apenas proclamar os direitos de todos."

Seguindo a mesma linha de raciocínio, Cândido Rangel Dinamarco (2003, p. 373) afirma que "[...], o acesso à justiça é a síntese de todos os princípios e garantias do processo [...]”. Nota-se, portanto, uma convergência quanto ao entendimento de que o acesso à justiça é o princípio elementar, a base de um sistema jurídico que busca oferecer garantias ao processo.

E como princípio elementar, o acesso à justiça proporciona outras garantias que Antônio Carlos de Araújo Cintra, Ada Pellegrini Grinover e Cândido Rangel Dinamarco (2007, p. 40) assim enumeram:

Assim, (a) oferece-se a mais ampla admissão de pessoas e causas ao processo (universalidade de jurisdição), depois (b) garante-se a todas elas (no cível e no criminal) a observância das regras que consubstanciam o devido processo legal, para que (c) possam participar intensamente da formação do convencimento do juiz que irá julgar a causa (princípio do contraditório), podendo exigir dele a (d) efetividade de uma participação em diálogo -, tudo isso com vistas a preparar uma solução que seja justa, seja capaz de eliminar todo resíduo de insatisfação. 
Dessa forma, o acesso à justiça deve ser entendido não só como acesso ao Poder Judiciário, mas à Justiça, no seu sentido mais amplo. É o princípio basilar de um ordenamento jurídico que visa garantir e promover a pacificação social.

\subsection{A Instrumentalidade do Processo e o Neoconstitucionalismo}

Cândido Rangel Dinamarco e Luiz Guilherme Marinoni abordam os temas da instrumentalidade do processo e do neoconstitucionalismo, com extremo conhecimento. E, tais assuntos possuem elevada importância no desenvolvimento do acesso à justiça.

A Jurisdição, serviço prestado pelo Estado, possui elementos objetivos de atuação, como características e princípios. $\mathrm{O}$ acesso à justiça também possui elementos objetivos, como a identificação de obstáculos e atitudes de transposição dos mesmos. Contudo, a existência de fatores objetivos, abordados isoladamente, não é suficiente para garantir a melhor integração entre prestação jurisdicional e acesso à justiça.

E é nesse ponto que a instrumentalidade do processo e o neoconstitucionalismo surgem como fatores primordiais. $\mathrm{O}$ processo e as normas constituem os principais elos entre a prestação jurisdicional e o acesso à justiça. Através deles a população conhece seus direitos e aciona o Estado para vê-los reconhecidos. Delinear nortes, sentidos, essências do que se pretende com a prestação jurisdicional e com o acesso à justiça, guiando o desenvolvimento das normas e dos processos, é de fundamental importância, na tentativa de proporcionar a pacificação social, de maneira plena. É nesse ponto que o aspecto subjetivo ganha relevância para o estudo.

A instrumentalidade do processo é defendida por Cândido Rangel Dinamarco, e busca atribuir ao processo uma obediência ao fim a que se destina, observando, sempre, a realidade que o rodeia. 
Já não basta aprimorar conceitos e burilar requintes de uma estrutura muito bem engendrada, muito lógica e coerente em si mesma, mas isolada e insensível à realidade do mundo em que deve estar inserida. Daí a proposta de colocar o próprio sistema processual como objeto de exame a ser feito pelo ângulo externo, ou seja, a partir da prévia fixação dos objetivos a perseguir e dos resultados com os quais ele há de estar permanentemente comprometido. (DINAMARCO, 2003, p. 11)

Dessa forma, o autor acima (2003, p. 11-12) busca dar efetividade ao processo, utilizando-se do fio da instrumentalidade para racionalizar as críticas e identificar os óbices à realização da missão recebida. Para ele, desmistificar as regras e formas do processo, otimizando o sistema, proporcionará a tão sonhada efetividade do processo.

A idéia-síntese que está à base dessa moderna visão metodológica consiste na preocupação pelos valores consagrados constitucionalmente, especialmente a liberdade e a igualdade, que afinal são manifestações de algo dotado de maior espectro e significação transcendente: o valor justiça. (DINAMARCO, 2003, p. 26)

Aqui, as ideias de Cândido Rangel Dinamarco e Luiz Guilherme Marinoni se aproximam, pois este último busca na constitucionalização do direito processual a efetivação do processo.

Neste norte, Luiz Guilherme Marinoni (2008, p. 46):

Por isso não há mais qualquer legitimidade na velha idéia de jurisdição voltada à atuação da lei; não é possível esquecer que o judiciário deve compreendê-la e interpretá-la a partir dos princípios constitucionais de justiça e dos direitos fundamentais.

A síntese do pensamento deste autor faz entender que a produção normativa deve obedecer a um controle que observe os princípios constitucionais, e seja adequada aos direitos funda- 
mentais. $\mathrm{O}$ jurista passa a assumir um papel de ator perante a jurisdição, revestido de maior dignidade e responsabilidade, deixando de ser apenas um aplicador de leis. (MARINONI, 2008)

O neoconstitucionalismo ${ }^{2}$ "exige a compreensão crítica da lei em face da Constituição”. Deve o jurista interpretar a lei e aplicá-la ao caso concreto, de forma que a mesma seja entendida como "conformação da lei". (MARINONI, 2008, p. 48)

É lícito concluir, ainda, que todo o direito processual constitucional constitui uma postura instrumentalista - , seja nessa instituição de remédios destinados ao zelo pela ordem constitucional, seja na oferta de garantias aos princípios do processo, para que ele possa cumprir adequadamente a sua função e conduzir a resultados jurídico-substanciais desejados pela própria Constituição e pela lei ordinária (tutela constitucional do processo). (DINAMARCO, 2003, p. 32)

Enfim, verifica-se que a instrumentalidade do processo e o neoconstitucionalismo/neoprocessualismo convergem para um mesmo sentido, buscando dar efetividade ao processo. Através dessas linhas de atuação, o processo observará as garantias constitucionais para proporcionar a conformação da lei, mas sem esquecer o fim a que se destina e a realidade do mundo em que está inserido, qual seja, promover o acesso à justiça.

\section{FATORES QUE INFLUENCIAM O DESENVOLVIMENTO DO ACESSO À JUSTIÇA}

\subsection{Exemplos de Obstáculos de Acesso à Justiça}

Considerando o entendimento de que o acesso à justiça engloba o acesso ao Judiciário e a todos os meios que garantam a efetivação da justiça da forma mais ampla, é preciso destacar

2 O neoconstitucionalismo irradiou-se para os demais ramos do direito, sendo responsável pelo surgimento do neoprocessualismo. 
alguns pontos que dificultam ou impedem que esse conceito atue em plenitude.

Maria Aparecida Lucca Caovilla (2003, p. 51) destaca que "o acesso à justiça deveria ser espontâneo, prático, ao alcance de todos.”, mas na prática o respeito a esse direito fundamental só se dá por meio do processo judicial, o que diminui a sua efetividade, em razão dos defeitos na estrutura do Estado.

Primeiramente, as custas judiciais são objeto de ataque por parte da doutrina, como óbice ao acesso à justiça para a maioria da população. $O$ alto custo para se demandar em juízo torna-se um grande vilão para a iniciativa dos indivíduos em ingressar com uma ação judicial. Aliados a isso, os honorários advocatícios também possuem custo elevado, devido à especialidade do serviço, o que afasta ainda mais aqueles que não possuem recursos financeiros.

Mauro Cappelletti e Bryant Garth (1988, p. 21) alertam que aqueles que possuem recursos financeiros consideráveis obtêm vantagens quanto aos seus adversários. Isto, porque podem pagar para litigar e também suportar a demora da demanda. Além disso, a parte economicamente mais favorecida pode gastar mais para produzir melhores provas e argumentos, influenciando diretamente na convicção do juiz.

É preciso eliminar as dificuldades econômicas que impeçam ou desanimem as pessoas de litigar ou dificultem o oferecimento de defesa adequada. A oferta constitucional de assistência jurídica integral e gratuita (art. $5^{\circ}$, inc. LXXIV) há de ser cumprida, seja quanto ao juízo civil como ao criminal, de modo que ninguém fique privado de ser convenientemente ouvido pelo juiz, por falta de recursos. A justiça não deve ser tão cara que o seu custo deixe de guardar proporção com os benefícios pretendidos. (CINTRA, GRINOVER e DINAMARCO, 2007, p. 40)

Outro empecilho importante contra o acesso à justiça é o tempo que duram os processos. Não bastasse o tempo natural 
que o processo precisa para se desenvolver, a espera por um provimento jurisdicional leva anos, e, em alguns casos, décadas, em razão da demanda e da falta de estrutura do Judiciário.

Isso afeta diretamente e de forma negativa a credibilidade do Poder Judiciário perante a população. Não bastasse tal descrédito, a própria noção de justiça fica abalada, sendo ainda mais desestimulada pelo descompasso entre operadores jurídicos e as necessidades sociais. (MATTOS, 2009, p. 79)

$\mathrm{O}$ excesso de burocracia nos atos processuais, a quantidade de trabalho nos juízos e a falta de estrutura e de pessoal para dar andamento sob o devido processo legal, acabam por abarrotar os gabinetes com processos que nunca terminam. E isso faz com que aqueles que necessitam da atuação do Poder Judiciário, pensem duas vezes antes de ingressar com uma ação em juízo e, às vezes, aceitam condições injustas para se verem livres dos conflitos.

Os efeitos dessa delonga, especialmente se considerados os índices de inflação, podem ser devastadores. Ela aumenta os custos para as partes e pressiona os economicamente fracos a abandonar suas causas, ou a aceitar acordos por valores muito inferiores àqueles a que teriam direito. (CAPPELLETTI e GARTH, 1988, p. 20)

Cândido Rangel Dinamarco (2003), ao tratar dos escopos do processo, expõe como escopo social a educação da sociedade, que interfere diretamente no desenvolvimento do Poder Judiciário. E esse é mais um dos obstáculos que dificultam a efetivação do acesso à justiça. $\mathrm{O}$ conhecimento dos seus direitos e dos meios capazes de garanti-los é um importante fator de acesso à justiça.

No entanto, a maioria da população brasileira não possui instrução adequada, capaz de lhe proporcionar plenitude no conhecimento de seus direitos.

Num primeiro nível está a questão de reconhecer a existência de um direito juridicamente exigível. 
Essa barreira fundamental é especialmente séria para os despossuídos, mas não afeta apenas os pobres. Ela diz respeito a toda a população em muitos tipos de conflitos que envolvem direitos. (CAPPELLETTI e GARTH, 1988, p. 22-23)

Fernando Pagani Mattos (2009, p. 82) ressalta que a população tem pouca consciência sobre os direitos que tem e dos meios disponíveis para a solução dos seus problemas. Mas o baixo desempenho educacional da população não é o único entrave ao efetivo acesso à justiça, no que diz respeito ao conhecimento de direitos. Infelizmente, os aplicadores do direito possuem um nível intelectual baixo, desinformados das extensões axiológicas e sociais dos acontecimentos, limitados à aplicação da norma como direito. Há uma aplicação extremamente técnica e literal das normas, longe da essência e do objetivo das leis. Esta também constitui uma importante barreira a ser transposta.

E, como conclusão dos estudos sobre as barreiras existentes ao acesso à justiça, Mauro Cappelletti e Bryant Garth (1998, p. 29) encerram:

Finalmente, como fator complicador dos esforços para atacar as barreiras ao acesso, deve-se enfatizar que esses obstáculos não podem simplesmente ser eliminados um por um. Muitos problemas de acesso são inter-relacionados, e as mudanças tendentes a melhorar o acesso por um lado podem exacerbar barreiras por outro. Por exemplo, uma tentativa de reduzir custos é simplesmente eliminar a representação por advogado em certos procedimentos. Com certeza, no entanto, uma vez que litigantes de baixo nível econômico e educacional provavelmente não terão a capacidade de apresentar seus próprios casos, de modo eficiente, eles serão mais prejudicados que beneficiados por tal "reforma". Sem alguns fatores de compensação, tais como um juiz muito ativo ou outras formas de assistência jurídica, os autores indigentes poderiam 
agora intentar uma demanda, mas lhes faltaria uma espécie de auxílio que lhes pode ser essencial para que sejam bem sucedidos. Um estudo sério do acesso à justiça não pode negligenciar o inter-relacionamento entre as barreiras existentes.

Enfim, considerando a existência de barreiras visíveis ao acesso à justiça, manifestadas de diversas formas, é preciso ter cuidado ao criar possibilidades de transposição das mesmas, observando suas características e interrelacionando-as entre si, para que possam ser eliminadas sem prejudicar o que existe de bom nelas e dá resultado.

\subsection{Principais Iniciativas de Promoção do Acesso à Justiça}

No Brasil, o acesso à justiça vem sendo ampliado, principalmente nos últimos 20 anos, a partir da Constituição da República de 1988, que trouxe expressamente o acesso à justiça, como um direito fundamental da população. No entanto, o assunto é tema de discussão há muito tempo, e mostra momentos que Mauro Cappelletti e Bryant Garth denominaram "ondas de acesso à justiça".

A primeira destas "ondas de acesso à justiça" voltase à criação de condições para propiciar o acesso à justiça aos pobres. A preocupação aqui espalhada repousa, fundamentalmente, na criação de mecanismos para que todos os cidadãos, independentemente de suas condições econômicas ou financeiras, tenham acesso ao "serviço judiciário" no sentido de que tenham condições concretas de requerer a proteção judicial (a tutela jurisdicional) nos casos em que ela se faz necessária e indispensável. (BUENO, 2008, p. 52)

A segunda "onda de acesso à justiça" está relacionada com os direitos e interesses difusos, como o meio-ambiente, por exemplo. Segundo Mauro Cappelletti e Bryant Garth (1988, 
p. 66-67), tais interesses exigem uma ação eficiente de grupos particulares, através de ações coletivas, advogados do interesse público e assessoria pública, para conduzir a população a reivindicar de forma eficiente esses interesses difusos.

Por fim, a terceira "onda de acesso à justiça" busca somar as duas ondas anteriores para proporcionar a plenitude do direito material. $\mathrm{O}$ processo passa a ser encarado como um realizador do direito material. (BUENO, 2008, p. 53-54)

Inúmeras alterações no ordenamento jurídico brasileiro foram promovidas, com vistas a ampliar as possibilidades de acesso à justiça e efetivar o que Mauro Cappelletti e Bryant Garth chamaram de "ondas de acesso à justiça". Dessa forma, cabe enumerar algumas das principais mudanças que serviram de incentivo a esse instituto.

\subsubsection{Justiça Gratuita, Assistência Judiciária e Assistência Jurídica Integral e Gratuita}

A justiça gratuita e a assistência judiciária gratuita buscam evitar que aqueles que não possuem recursos financeiros sejam obstados de defender seus direitos em juízo ou fora dele. Pode-se chegar a essa conclusão com base nas definições apresentadas por Augusto Tavares Rosa Marcacini (2003, p. 31):

Por justiça gratuita, deve ser entendida a gratuidade de todas as custas e despesas, judiciais ou não, relativas a atos necessários ao desenvolvimento do processo e à defesa dos diretos do beneficiário em juízo. O benefício da justiça gratuita compreende ao pleno exercício dos direitos e das faculdades processuais, sejam tais despesas judiciais ou não.

[...]

A assistência judiciária envolve o patrocínio gratuito da causa por advogado. A assistência judiciária é, pois um serviço público organizado, consistente na defesa em juízo do assistido, que deve ser oferecido pelo Estado, mas que pode ser desempenhado por 
entidades não-estatais, conveniadas ou não com o Poder Público.

No Brasil, na década de 50, foi promulgada a Lei 1.060/50, que estabelece normas para a concessão de assistência judiciária aos necessitados. Os principais limites dessa garantia estão previstos nos artigos $2^{\circ}, 3^{\circ}$ e $4^{\circ}$ da Lei. $\mathrm{O}$ art. $2^{\circ}$, parágrafo único, estabelece que será considerado necessitado todo aquele que a situação econômica não permita pagar custas e honorários de advogado, sem prejuízo do próprio sustento e de sua família. $\mathrm{O}$ art. $4^{\circ}$ prevê que mediante simples afirmação na própria petição inicial, o interessado poderá provar sua condição de necessitado, conforme estabelecido no art. $2^{\circ}$.

Dentre as isenções que a Lei garante:

Art. 30 A assistência judiciária compreende as seguintes isenções:

I - das custas judiciárias e dos selos;

II - dos emolumentos e custas devidos aos juízes, órgãos do Ministério público e serventuários da Justiça;

III - das despesas com as publicações indispensáveis no jornal encarregado da divulgação dos atos oficiais;

IV - das indenizações devidas às testemunhas que, quando empregados, receberão do empregador salário integral, como se em serviço estivessem, ressalvado o direito regressivo contra o poder público federal, no Distrito Federal e nos Territórios; ou contra o poder público estadual, nos Estados;

V - dos honorários de advogado e peritos;

VI - das despesas com a realização do exame de código genético - DNA que for requisitado pela autoridade judiciária nas ações de investigação de paternidade.

Com a Constituição de 1988, a assistência judiciária e a justiça gratuita foi ampliada pelo art. 5, LXXIV. Através dele, 
o Estado fica obrigado a prestar assistência jurídica integral e gratuita àqueles que provarem não possuir recursos. Dessa forma, "o Estado tem o dever de atuar em prol da conscientização jurídica da sociedade, orientando-a com relação aos seus direitos.” E mais, busca evitar que o custo inerente à prestação jurisdicional torne-se um obstáculo para os que não possuem recursos. Ocorre uma transferência da responsabilidade por estes custos para o próprio Estado, evitando o não acesso à justiça em decorrência deste fator. (BUENO, 2008, p. 140)

Diversos autores, dentre eles Maria Aparecida Lucca Caovilla (2003) e Fernando Pagani Mattos (2009) defendem, ainda, que a assistência jurídica não se refere apenas à fase processual. Deve haver acompanhamento pré-processual, extrajudicial e inclusive administrativo, quando for o caso. Com isso, surge outro problema, decorrente do inter-relacionamento das questões que envolvem o acesso à justiça.

A assistência judiciária, no entanto, não pode ser o único enfoque a ser dado na reforma que cogita do acesso à Justiça. Existem limites sérios na tentativa de solução pela assistência judiciária. Antes de mais nada, para que o sistema seja eficiente, é necessário que haja um grande número de advogados, um número que pode até exceder a oferta, especialmente em países em desenvolvimento. (CAPPELLETTI e GARTH, 1988, p. 47)

Ou seja, da assistência judiciária gratuita oferecida pela Lei 1.060/50 até a ampliação indicada pela Constituição Federal, com a assistência jurídica integral e gratuita existe um abismo ainda intransponível, pois o Estado não se responsabilizou apenas pela isenção de custas e honorários no curso dos processos judiciais. Mas sim, pela orientação jurídica integral dentro e fora do Poder Judiciário.

Por isso, da afirmação de Mauro Cappelletti e Bryant Garth fica claro que, como visto anteriormente, não basta derrubar as barreiras, isoladamente, assim como também não basta criar 
soluções individualizadas, pois o acesso à justiça é composto de ações conjuntas, no seu combate e no seu desenvolvimento.

\subsubsection{Advocacia Dativa e Defensoria Pública}

A Defensoria Pública está prevista no art. 134 da Constituição Federal, e é considerada instituição essencial à função jurisdicional do Estado. A ela cabe prestar orientação jurídica e a defesa, em todos os graus, àqueles que forem considerados necessitados, conforme estabelecido pelo art. $5^{\circ}$, LXXIV.
A institucionalização da Defensoria Pública (Const., art. 134) constitui séria medida direcio- nada à realização da velha e descumprida promessa constitucional de assistência judiciária aos necessi- tados. A Constituição fala agora, mais amplamente, em "assistência jurídica integral e gratuita" (art. 5\%, inc. LXXIV), a qual inclui também o patrocínio e orientação em sede extrajudicial (advocacia preven- tiva); o emprego do adjetivo jurídica, em vez de judiciária, foi ditado exatamente por essa intenção de ampliar a garantia. (CINTRA, GRINOVER e DINAMARCO, 2007, p. 237)

Conforme Fernando Pagani Mattos (2009, p. 97), a Defensoria Pública obedece à finalidade precípua de oferecer assistência jurídica completa. Ao Estado cabe criar e subsidiar tal órgão, a fim de proporcionar à população o conhecimento de quais são os seus direitos, como devem agir etc.

O $\S 1^{\circ}$ do art. 134 da CF estabelece que Lei complementar organizará a Defensoria Pública da União, do Distrito Federal e dos Territórios, e prescreverá normas gerais para a organização nos Estados. Assim, é de responsabilidade dos Estados membros criarem e organizarem essas instituições, para o fim de efetivar um direito garantido constitucionalmente.

Com isso, a implantação de Defensorias Públicas importa não somente em benefício para população em geral, mas também para os operadores do direito, pois amplia as formas de atuação 
do profissional. Todavia, é preciso compreender que o Estado não possui recursos suficientes para arcar com esse serviço de maneira incondicional, razão pela qual essa instituição ainda encontra inúmeras dificuldades para se consolidar.

Enfim, mesmo com algumas dificuldades na ultrapassagem das barreiras existentes ao acesso à justiça, é de se concordar com José Afonso da Silva (2006, p. 607) quando ele afirma que a Constituição deu um passo importante ao colocar a Defensoria Pública como instituição essencial à função jurisdicional.

\subsubsection{Juizados Especiais}

Os Juizados Especiais, antes conhecidos como Juizados de Pequenas Causas, foram instituídos pela Lei 9.099/95 em âmbito estadual, e pela Lei 10.259/01 em âmbito federal, em razão do que determina o art. 98 da CF. Através delas buscou-se simplificar alguns procedimentos, com o objetivo de prestar a tutela jurisdicional de forma mais rápida e menos complicada.

A CF, no art. 98, I, impõe à União, no Distrito Federal e nos Territórios (inexistentes agora), e aos Estados a criação de juizados especiais, providos por juízes togados, ou togados e leigos, competentes para a conciliação, o julgamento e a execução de causas cíveis de menor complexidade e infrações penais de menor potencial ofensivo, mediante os procedimentos oral e sumaríssimo, permitidos, nas hipóteses previstas em lei, a transação e o julgamento de recursos por turmas de juízes de primeiro grau. A EC-22/99, acrescentando parágrafo único no art. 98, autorizou a criação de juizados especiais também na Justiça Federal. (SILVA, 2006, p. 583)

A instituição desses juizados busca diminuir o volume de processos que abarrotam o Poder Judiciário atualmente, em suas varas comuns, proporcionando um rito mais rápido e menos burocrático, para efetivar a prestação jurisdicional em tempo hábil. Mas, em nenhum momento, tais juizados estão dispensados de garantir o contraditório, a ampla defesa e o devido processo legal. 
Há que se esclarecer que tanto a Lei n. 9.099 de 26 de setembro de 1995, como a Lei n. 10.251 (sic) de 12 de julho de 2001, abarcam peculiaridades e objetivos específicos, especialmente o de oportunizar ao cidadão uma justiça moderna, eficiente e ágil, prevalecendo os princípios da desburocratização e simplificação do processo e dos procedimentos, possibilitando que a simplicidade e a oralidade alcancem a sua finalidade maior, qual seja, a de oportunizar o efetivo acesso à justiça à população. (CAOVILLA, 2003, p. 172)

Infelizmente os juizados especiais já não correspondem às expectativas iniciais. Atualmente os tribunais de pequenas causas são tão complexos, dispendiosos e lentos, quanto os juízos regulares. Isso porque juízes e até mesmo a presença de advogados, todos sem abandonar o velho formalismo tradicional, acabam por impedir que esses juizados caminhem de forma mais rápida. (CAPPELLETTI e GARTH, 1988, p. 96-97)

No entanto, mesmo com essas peculiaridades, os Juizados Especiais constituem grande avanço na busca da efetivação do acesso à justiça, aproximando a população do Poder Judiciário, na medida em que dispensa a presença de advogados em alguns casos, não exige o pagamento de custas processuais e apresenta linguagem mais simples, enfatizando o princípio da oralidade em grau máximo e a informalidade.

\subsubsection{Processo Judicial Eletrônico}

O processo eletrônico é uma realidade no sistema jurídico atual, e vem ganhando maior espaço e com mais rapidez perante os Tribunais do país. Isso deve-se não só ao fato de que a informatização judicial é um caminho de mão única, mas também principalmente pelos avanços que tal inovação vem proporcionando ao efetivo acesso à justiça e à adequada prestação jurisdicional.

Em 19 de dezembro de 2006 foi editada a Lei 11.419/06, que dispõe sobre a informatização do processo judicial e altera o Código de Processo Civil de 1973. Tal lei visa modernizar a 
prestação jurisdicional, para que esta seja capaz de efetivar o acesso à justiça, no âmbito civil, penal e trabalhista.

Dentre as novidades trazidas pela lei, está a possibilidade do envio de petições e recursos, além da prática de atos processuais por meio eletrônico, direto do escritório do advogado ou da casa do jurisdicionado, mediante o uso de assinatura eletrônica. Também o art. $3^{\circ}$, parágrafo único, inova quanto aos prazos judiciais, permitindo a transmissão da petição eletrônica até às 24 horas do último dia do prazo.

O processo eletrônico está acessível pela internet permanentemente para todos os interessados. Não há nenhum impedimento para que o interessado consulte o processo quando bem entender, bem assim que protocole (anexe) um requerimento ou petição a qualquer momento. Ainda que o processo esteja "concluso" com o julgador, o advogado poderá peticionar. Também desaparece a tradicional carga dos autos, já que é sempre possível o acesso imediato do processo de qualquer lugar do mundo, pela web. (GARCIA, 2006, p. 51)

Um ponto extremamente relevante no estudo do processo judicial eletrônico, e que é motivo de receio e crítica daqueles que ainda não dão o efetivo valor ao processo eletrônico, é o acesso da população a equipamentos eletrônicos capazes de concretizar os artigos desta lei. O parágrafo 3o do art. 10 prevê que o Poder Judiciário deverá manter esses equipamentos à disposição de todos os interessados. Isso busca evitar que aquele que necessita da prestação jurisdicional se afaste dela por não ter acesso aos equipamentos necessários.

Inúmeros ajustes, testes e procedimentos vêm sendo estudados e implementados, para que o processo eletrônico possa, cada vez mais, atingir seus objetivos. E, atentos ao desenvolvimento que o processo eletrônico vem obtendo com o passar do tempo, o CNJ, em notícia veiculada através de seu sítio na internet, no dia 15 de setembro de 2009, divulgou os acordos referentes à implantação da segunda geração de processo eletrô- 
nico, a ser adotado por todos os Tribunais Regionais Federais, uniformizando os sistemas e automatizando atividades.

Também o STJ e o STF estão atentos às inovações proporcionadas pelo processo eletrônico, possibilitando a tramitação eletrônica. A Resolução no 417 de outubro de 2009 regulamentou definitivamente a tramitação por via eletrônica no STF, fazendo com que todos os processos sejam encaminhados através do protocolo eletrônico, possibilitando a tramitação por meio do "e-STF".

Enfim, cada vez mais os Tribunais de todo o país vêm se mobilizando para implantarem sistemas de processo eletrônico, preferencialmente seguindo um modelo padrão e, permitindo a interligação entre eles, possibilitando uma melhor prestação jurisdicional, mais célere e mais efetiva, e, ainda, mais acessível a toda a população, reduzindo custos, distâncias, barreiras etc.

O acesso à justiça é tema de extrema relevância no âmbito do Poder Judiciário, pois não basta aprimorar métodos, desenvolver sistemas e reduzir burocracia na prestação jurisdicional, se não for possível fazer com que tais melhoramentos cheguem efetivamente ao encontro do jurisdicionado. Dessa forma, o processo eletrônico, que já demonstrou inúmeros avanços no que diz respeito à prestação jurisdicional, também representa grandes avanços no que diz respeito ao acesso à justiça.

Relembrando alguns obstáculos ao acesso à justiça, anteriormente enumerados, pode-se observar o quanto o processo eletrônico combate incisivamente as custas judiciais. Ao processar um feito em autos totalmente virtuais, a economia com papel, tinta das impressoras, espaço para armazenamento físico, tempo de tramitação, combustível nos deslocamentos ao fórum etc., permitem que todos esses recursos sejam realocados para novos sistemas, investimento em equipamentos, na qualificação dos serventuários da justiça e, para os causídicos, especialmente, melhores condições de trabalho, haja vista o aumento no tempo que passam a ter para estudar suas causas, produzir melhores peças, estarem mais disponíveis para seus clientes etc. 
Mas, o ponto mais importante é com certeza a economia de tempo para os jurisdicionados. É aí que efetivamente o conceito de acesso à justiça brilha, visto a capacidade de tramitar-se um processo com mais rapidez, levando a tutela jurisdicional tempestivamente e, consequentemente, correspondendo aos anseios da população.

Ao lado da assistência jurídica integral e gratuita, das defensorias públicas e da instituição dos Juizados Especiais, o processo eletrônico é sem dúvida, um grande incentivador do acesso à justiça no Brasil e, vai ao encontro do que Mauro Cappelletti e Bryant Garth chamaram de "ondas de acesso à justiça", principalmente na terceira onda.

\section{SITUAÇÃO DO ACESSO À JUSTIÇA NO ESTADO DE SANTA CATARINA}

O Estado de Santa Catarina pode ser considerado um ente privilegiado quando o assunto é acesso à justiça. As barreiras anteriormente citadas possuem contornos menores neste Estado, assim como os meios de promoção do acesso à justiça tendem a ter maior efetividade.

Isso porque, o Estado de Santa Catarina possui nível de educação da população superior a maioria dos outros Estados. Conforme alguns resultados preliminares divulgados no sítio do IBGE na internet, a respeito do Censo 2010, o Estado Catarinense possui cerca de $88 \%$ da população alfabetizada (considerando-se apenas pessoas acima de 5 anos de idade). Esse percentual é igual ao dos Estados do Rio Grande do Sul, São Paulo e Distrito Federal e, apenas o Estado do Rio de Janeiro possui índice melhor, com cerca de 89\%. Todos os demais Estados possuem percentual de alfabetização inferior ao de Santa Catarina, o que demonstra o elevado grau de instrução deste Estado e uma melhor condição de acesso à justiça, frente ao nível de educação de sua população, potencialmente mais consciente dos seus direitos. 
Apenas para complementar, o Estado de Alagoas obteve um índice de apenas $68 \%$ (considerados os mesmos parâmetros de pesquisa), o que naturalmente diminui as condições de acesso à justiça naquele Estado, tendo em vista que um menor grau de informação gera, consequentemente, um desconhecimento sobre os direitos e afasta a população da justiça.

Outro fator de extrema relevância no desenvolvimento ao acesso à justiça diz respeito ao valor cobrado a título de custas judiciais. E, mais uma vez o Estado de Santa Catarina merece destaque. Segundo notícia veiculada no sito do Tribunal de Justiça de Santa Catarina na internet em 25-3-2011, o Estado está entre os 3 (três) entes da federação que cobram o menor valor de custas judiciais, ao lado de São Paulo e do Distrito Federal. Conforme as declarações contidas na notícia, o valor conjuga um percentual máximo de $1 \%$ sobre o valor da causa, respeitando limites mínimo e máximo entre 20 e 400 URCs (Unidade de Referência de Custas). Isso significa que, em média, a variação das custas fica entre $R \$ 100,00$ e $R$ 2.800,00.

Aliado ao valor das custas judiciais, os honorários advocatícios são um grande empecilho, principalmente para a população de mais baixa renda. Por isso, a instituição da assistência jurídica integral e gratuita, através do art. 5, LXXIV, da CF, possui extrema relevância, impondo ao Estado, assim entendido como ente federativo, arcar com tais gastos para àqueles que não tiverem condições de pagar, sem prejuízo do próprio sustento e de sua família.

No mesmo norte, está a determinação da criação das defensorias públicas nos Estados, conforme o art. 134, da Constituição. No entanto, até o ano de 2006 o Estado de São Paulo ainda não possuía Defensoria Pública estadual e, no Estado do Paraná somente neste ano de 2011 foi instituída a sua Defensoria Pública. Com isso, o Estado de Santa Catarina é o único ente da federão em que tal instituição ainda não foi criada.

Especificamente no Estado de Santa Catarina, a orientação e a defesa dos necessitados são feitas através da Defen- 
soria Dativa, organizada pela Ordem dos Advogados do Brasil, Seção de Santa Catarina. Isto porque através do art. 10 da Lei Complementar no 155/97 do Estado de Santa Catarina, ficou instituída a Defensoria Pública, exercida através da Defensoria Dativa e Assistência Judiciária Gratuita.

Santa Catarina é o único Estado da Federação que não possui a Instituição Defensoria Pública, o que de certa maneira causa alguns prejuízos à população e aos próprios advogados que exercem sua profissão através da Defensoria Dativa. Segundo Maria Aparecida Lucca Caovilla (2003), a dívida do Estado referente aos honorários dos advogados que prestaram assistência através da defensoria dativa, atinge cifras milionárias, e o atraso no pagamento de tais verbas está cada vez maior.

Assim, o plus oferecido pela Defensoria Pública em relação à assistência dativa prestada por profissionais particulares subsidiados pelo Estado reside na maior amplitude de sua atuação, haja vista que permite desenvolver junto à população a noção de cidadania por meio da educação. Assim, evita-se a criação de litígios em virtude da informação do indivíduo e se proporciona o estabelecimento de uma ordem jurídica justa mais palpável, mediante o atendimento das necessidades sociais enquanto política pública de acesso à justiça. (MATTOS, 2009, p. 98)

Todavia, não se pode deixar de considerar que a prestação de assistência jurídica por advogados dativos é de extrema relevância. Além de atuarem em todos os municípios, o que não é viável através de uma Defensoria Pública, permite o desenvolvimento de jovens advogados, capacitando-os e abrindo portas no mercado de trabalho.

No que tange aos Juizados Especiais, novamente o Estado Barriga Verde anda na frente. Com o intuito de ampliar os resultados obtidos nos Juizados através da conciliação, o Tribunal de Justiça de Santa Catarina desenvolveu o programa Acadêmico Conciliador. 
O projeto Acadêmico Conciliador, desenvolvido pela Secretaria do Conselho Gestor dos Juizados Especiais e Programas Alternativos de Solução de Conflitos do TJSC, tem por objetivo capacitar estudantes de Direito para atuarem voluntariamente nas atividades de conciliação junto ao judiciário - nos juizados especiais cíveis e criminais. A eles são concedidos incentivos como pontuação extra para concurso da magistratura, validação de estágio obrigatório e, ainda, o aumento do conhecimento teórico-prático na área jurídica. (ABREU, 2008, p. 248)

O TJSC também lançou outra iniciativa de grande relevância, chamada Casa da Cidadania, cujo objetivo é levar os juizados da cidadania a todos os municípios que não sejam sede de comarca (ABREU, 2008, p. 244-245). Ou seja, mesmo naquelas cidades mais interioranas onde não é necessário, nem viável a instalação de uma comarca, o Tribunal de Justiça busca se aproximar da população através das Casas da Cidadania.

Não bastasse isso, liderando a vanguarda dos Tribunais que buscam alternativas para efetivar a prestação jurisdicional e ampliar o acesso à justiça, o Judiciário Catarinense foi pioneiro ao instalar a Câmara Regional de Chapecó, como forma de descentralizar o julgamento em $2^{\circ}$ grau, dando concretude ao disposto no art. $125, \S 6^{\circ}$, da Constituição federal. (notícia veiculada no sítio do TJSC na internet em 4-2-2009)

Por fim, cabe destacar a virtualização do processo judicial como forma de ampliação dos horizontes do acesso à justiça. Em Santa Catarina a Justiça Federal, a Justiça do Trabalho e o Judiciário Catarinense já possuem processos que tramitam totalmente em autos virtuais, em algumas varas. Conforme explanado anteriormente, a virtualização dos processos judiciais irá contribuir muito para a democratização da justiça e aceleração do tempo necessário para solucionar um conflito. Assim, o Estado demonstra estar em sintonia com os rumos tecnológicos e investindo na promoção do acesso à justiça. 


\section{CONCLUSÃO}

O acesso à justiça pode ser considerado o mais básico dos direitos humanos, tendo por objetivo promover a justiça social. Por isso, o fio da instrumentalidade do processo, aliado ao neoconstitucionalismo, possuem grande relevância no cenário da interpretação atualmente, otimizando o sistema para os fins a que se destina e observando sempre os princípios constitucionais do processo.

Como visto, os obstáculos existentes devem ser ultrapassados de maneira harmônica, considerando a interdependência que existe entre eles, e as iniciativas de promoção do acesso à justiça devem sempre estar atentas à realidade que os cerca, para poder dar a maior efetividade possível ao seu fim.

Especificamente no Estado de Santa Catarina, quando o assunto é acesso à justiça, pode-se considerar que se trata de um ente privilegiado. Conforme verificado, o nível educacional da população catarinense, em geral está entre os mais altos do país, o que permite presumir estar-se diante de uma sociedade melhor conhecedora dos seus direitos. Aliado a isso, o valor das custas judiciais é um dos 3 mais baixos do Brasil, facilitando o ajuizamento de ações por todos os cidadãos que pretendem ver seus conflitos resolvidos pelo Judiciário.

No que tange aos Juizados Especiais, Santa Catarina mais uma vez anda na vanguarda do sistema, instituindo as Casas da Cidadania e incentivando a conciliação através do projeto Acadêmico Conciliador. Da mesma forma, a tecnologia empregada pelo Poder Judiciário, tanto Federal quanto Estadual, mostra a modernização que vem sendo empregado nos processos, através do processo eletrônico, dando celeridade e simplicidade aos atos judiciais.

Talvez um dos únicos pontos negativos do Estado, quando se aborda o tema do acesso à justiça, é a ausência de Defensoria Pública em Santa Catarina. Apesar da existência da defensoria dativa, que desenvolve um trabalho relevante, a criação daquele 
órgão é de fundamental importância para ampliar e melhorar a prestação de assistência jurídica integral e gratuita, conforme estipulado na Constituição Federal.

Em síntese, o Estado de Santa Catarina é um ente comprometido com a promoção e desenvolvimento do acesso à justiça. No entanto, ainda existem obstáculos a serem ultrapassados e aspectos a serem melhorados.

\begin{abstract}
Faced with the slowness of the Judiciary recognized the growing demand and the filing of action, which causes immense distrust of the population in that agency, identifying obstacles and developing ways for promoting and expanding access to justice is a matter of fundamental importance when seeking to give effect to the constitutionals dictates. Specifically in the State of Santa Catarina can be seen that the barriers have soft contours and the initiatives of development to the access find strength and effectiveness. The negative point is registered by the lack of Public Defense in this federative entity.
\end{abstract}

Keywords: Justice access. Legal assistance. Special courts. Public defense. State of Santa Catarina.

\title{
REFERÊNCIAS
}

ABREU, Pedro Manoel. Acesso à Justiça e Juizados Especiais: O desafio histórico da consolidação de uma justiça cidadã no Brasil. 2a Ed. Florianópolis: Conceito Editorial, 2008, 282 p.

BRASIL, Constituição da República Federativa do Brasil. Publicada no D.O.U. de 5 de outubro de 1988. Disponível em: 〈www.presidencia.gov.br〉. Acesso em: 15 ago. 2011.

BRASIL, Lei 1.060 de 05 de fevereiro de 1950. Estabelece normas para a concessão de assistência judiciária aos necessitados. Publicada no D.O.U. de 13.02.1950. Disponível em: 〈www.presidencia.gov.br〉. Acesso em: 15 ago. 2011. 
BRASIL, Lei 9.099 de 26 de setembro de 1995. Dispõe sobre os Juizados Especiais Cíveis e Criminais e dá outras providências. Publicada no D.O.U. de 27.09.1995. Disponível em: 〈www.presidencia.gov.br>. Acesso em: 15 ago. 2011.

BRASIL, Lei 10.259 de 12 de julho de 2001. Dispõe sobre a instituição dos Juizados Especiais Cíveis e Criminais no âmbito da Justiça Federal. Publicada no D.O.U. de 13.07.2001. Disponível em: <www.presidencia.gov. br>. Acesso em: 15 ago. 2011.

BRASIL, Lei 11.419 de 19 de dezembro de 2006. Dispõe sobre a informatização do processo judicial. Publicada no D.O.U. de 20.12.2006. Disponível em: 〈www.presidencia.gov.br>. Acesso em: 15 ago. 2011.

BUENO, Cássio Scarpinella. Curso sistematizado de direito processual civil: teoria geral do direito processual civil, 1. 2a Ed. São Paulo: Saraiva, 2008.

CAPPELLETTI, Mauro e GARTH, Bryant. Acesso à Justiça. Porto Alegre: Fabris, 1988. 168 p.

CAOVILLA, Maria Aparecida Lucca. Acesso à Justiça e Cidadania. Chapecó: Argos, 2003. 233 p.

CINTRA, Antônio Carlos de Araújo, GRINOVER, Ada Pellegrini e DINAMARCO, Cândido Rangel. Teoria Geral do Processo. 23a Ed. São Paulo: Malheiros editores. 2007. 383 p.

CONSELHO NACIONAL DE JUSTIC̣A. Disponível em <www.cnj.jus. br>. Acesso em 30 out. 2009.

DINAMARCO, Cândido Rangel. A Instrumentalidade do Processo. 11ª Ed. São Paulo: Malheiros, 2003. 413 p.

GARCIA, Sérgio Renato Tejada. Informatização e prestação jurisdicional: desafios e perspectivas. Revista jurídica. Porto Alegre: Editora Notadez. Ano $54, n^{\circ} 340$, fevereiro de 2006

INSTITUTO BRASILEIRO DE GEOGRAFIA E ESTATÍSTICA. Disponível em www.censo2010.ibge.gov.br/primeiros_dados_divulgados. Acesso em 13 ago. 2011

INSTITUTO BRASILEIRO DE GEOGRAFIA E ESTATÍSTICA. Disponível em www.ibge.gov.br/home/estatistica/populacao/censo2010/ resultados_preliminares. Acesso em 13 ago. 2011. 
JUSTIÇA FEDERAL SEÇÃO JUDICIÁRIA DE SANTA CATARINA. Disponivel em <www.jfsc.jus.br>. Acesso em 28 ago. 2009.

MATTOS, Fernando Pagani. Acesso à Justiça. Um princípio em busca de efetivação. Curitiba: Juruá, 2009. 144p.

MARCACINI, Augusto Tavares Rosa. Assistência jurídica, assistência judiciária e justiça gratuita. Rio de Janeiro: Forense, 2003.

MARINONI, Luiz Guilherme. Curso de Processo Civil. Teoria Geral do processo. Vol. 1. São Paulo: Editora RT. 2008.

SANTA CATARINA, Lei Complementar 155 de 15 de abril de 1997. Institui a Defensoria Pública no Estado de Santa Catarina. Publicada no D.O. de 15.04.1997. Disponível em: <www.alesc.sc.gov.br>. Acesso em: 20 ago. 2009.

SILVA, José Afonso. Curso de Direito Constitucional Positivo. 27ª Ed. São Paulo: Malheiros editores. 2006. 925 p.

SUPERIOR TRIBUNAL DE JUSTIÇA. Disponivel em 〈www.sti.jus.br>. Acesso em 19 ago. 2009.

SUPREMO TRIBUNAL FEDERAL. Disponível em <WWW.stf.jus.br>. Acesso em 19 ago. 2009.

TRIBUNAL DE JUSTIÇA DE SANTA CATARINA. Disponível em www. tjsc.jus.br/noticias. Acesso em 13 ago. 2011.

TRIBUNAL REGIONAL FEDERAL DA 4a REGIÃO. Disponível em <www.trf4.jus.br>. Acesso em 28 ago. 2009. 